\title{
A produção escrita de histórias por crianças e sua relação com as habilidades de leitura e escrita de palavras/pseudopalavras
}

\author{
Jerusa Fumagalli de Salles ${ }^{a^{*}}$, Jane Correa ${ }^{b}$ \\ ${ }^{a}$ Departamento de Psicologia do Desenvolvimento e da Personalidade, Instituto de Psicologia, Universidade Federal do Rio Grande do \\ Sul, Porto Alegre, RS, Brasil; ' ${ }^{b}$ Departamento de Psicologia Geral e Experimental, Instituto de Psicologia, Universidade Federal do Rio de \\ Janeiro, Rio de Janeiro, RJ, Brasil
}

Resumo: O estudo descreve a produção escrita de histórias de crianças do $3^{\circ}$ ano de escolas públicas e compara-a entre subgrupos por habilidades de leitura e escrita de palavras/pseudopalavras. As produções textuais foram enquadradas em uma de cinco categorias: $54,6 \%$ da amostra atingiram categorias intermediárias (III e IV), caracterizando-se por ausência de uma situação-problema ou apenas esboço desta. Há uma associação significativa entre as habilidades no nível da palavra e a produção de texto narrativo escrito. Crianças que são hábeis na leitura e escrita de palavras/ pseudopalavras também são hábeis na produção escrita de textos. $O$ inverso também é verdadeiro. $O$ domínio das correspondências grafofonêmicas regulares na leitura e na escrita parece ser importante para produção escrita de texto narrativo. No entanto, a habilidade na leitura de palavras irregulares parece mais importante do que na escrita de palavras irregulares para a produção escrita de histórias.

Palavras-chave: linguagem escrita, escrita de histórias, crianças, produção textual, avaliação.

Em uma sociedade letrada, o uso competente da linguagem escrita torna-se um imperativo para se lidar com atividades sociais e comunicativas diversas em uma variedade de contextos culturais (Rojas-Drummond, Albarrán, \& Littleton, 2008). Entre as competências implicadas neste uso inclui-se a habilidade de escrita de textos. Produzir textos escritos envolve a seleção do conteúdo do texto (processamento pragmático e semântico); tradução em formato linguístico (palavras, sentenças) e em um plano motor da sequência de movimentos (Belinchón, Igoa, \& Rivière, 2000), além de envolver o acesso a uma série de conhecimentos, como normas de notação da escrita, normas gramaticais de marcação de concordância, recursos coesivos, sinais de pontuação, utilização de conhecimentos acerca do tipo de texto e organização e sequência de ideias (Leal \& Luz, 2001). Engloba, portanto, a capacidade da criança de refletir acerca dos aspectos microlinguísticos do texto, como os coesivos e a pontuação, e dos aspectos macrolinguísticos, como organização geral do texto, seu conteúdo e sua estrutura, como noções sobre gêneros textuais (Spinillo \& Simões, 2003). Ser um escritor proficiente significa ser hábil em aportar às formas linguísticas flexibilidade em uma variedade de contextos comunicativos, uma habilidade que requer desenvolvimento sociocognitivo e experiências pragmáticas e linguísticas (Berman, 2008).

A escrita se realiza por meio de gêneros de texto, que se caracterizam por conteúdo e estrutura que lhes são

*Autora correspondente: jerusafs@yahoo.com.br próprios (Marcuschi, 2008). A história, como gênero de texto, caracteriza-se por uma sequência de acontecimentos reais ou fictícios, situados em espaço e tempo determinados, cujo conteúdo é expresso por meio do discurso narrativo (Costa, 2008). A estrutura narrativa de uma história prototípica inclui basicamente três elementos: início, desenvolvimento e desfecho. No início da história, ocorre a introdução da cena e dos personagens. No seu desenvolvimento, há o aparecimento de uma situação-problema ou o surgimento de um clímax, que se resolve ou se dissolve no desfecho da história.

Baseada na estrutura narrativa da história prototípica, Lins e Silva e Spinillo (2000) propuseram uma classificação hierárquica aplicável à análise da produção de histórias por crianças. Tal classificação permitiria, então, avaliar o domínio do esquema narrativo de histórias por crianças. Foram descritos cinco níveis de domínio da estrutura narrativa. Os dois primeiros são níveis mais elementares de esquema narrativo e de produção de histórias. No Nível I, as histórias limitam-se à apresentação dos personagens e/ou cenário. No Nível II, a história reúne apenas eventos que se sucedem. A partir do Nível III, as crianças são capazes de incluir uma situação-problema ou clímax em suas histórias. Os níveis se distinguem em função da habilidade da criança em prover um desfecho à história tanto mais articulado ao desenvolvimento da trama quanto possível. No Nível III, o desfecho é ausente ou abrupto, não articulado à situação problema. No Nível IV, o desfecho mostra-se, ainda, pouco elaborado, não explicitando os meios pelos quais a situação-problema foi resolvida. No Nível V estão as histórias completas, com desfecho elaborado, articulado à trama. Crianças nas séries iniciais 
do ensino fundamental tenderiam a produzir histórias nos primeiros níveis de organização da estrutura narrativa, enquanto os níveis mais avançados estariam associados ao progresso na escolaridade, já caracterizando um número expressivo de produções escritas a partir do $4^{\circ}$ ano do ensino fundamental (Lins e Silva \& Spinillo, 2000).

A avaliação da produção escrita de histórias pode se feita a partir de: uma figura (Yorkston, Jaffe, Polissar, Liao, \& Fay, 1997); sequências de gravuras, história ouvida, produção de história oral (a criança elabora oralmente uma história original e depois a escreve); produção livre de uma história original (Lins e Silva \& Spinillo, 2000); um filme sem palavras (Berman, 2008); desenho feito pela criança de um cenário (em um editor de imagens) (Rodrigues, Queiroz, \& Alencar, 2008); ou atividade de grupo, na qual as crianças buscam juntas ideias para as histórias, integram estas ideias em um plano e trabalham para construir um texto coerente (Rojas-Drummond et al., 2008).

O contexto ou situação de produção tem bastante influência na escrita de histórias pelas crianças (Ferreira \& Correa, 2008; Pessoa, Correa \& Spinillo, 2010). Em termos gerais, contextos que fornecem algum tipo de apoio à criança, seja visual ou linguístico, auxiliam-na a produzir histórias mais elaboradas do que as que produziria sem tais apoios. Rodrigues et al. (2008) analisaram textos produzidos por crianças de 7 ( $2^{\circ}$ ano) e de 9 anos de idade $\left(4^{\circ}\right.$ ano) na condição de desenho e depois escrita e no contexto inverso (escrita e depois desenho). Foi avaliada a inclusão de elementos mágicos, explicação mágica, a resolução da situação-problema sem coerência, o desfecho com mudança de tópicos, a inclusão de personagens exteriores à história, a explicação causal, a resolução da situação-problema não explicada, o desfecho não elaborado, a intenção do personagem, a resolução da situação-problema explicada e o desfecho elaborado. A única diferença estatisticamente significativa entre grupos de idades diferentes foi a presença de explicação psicológica, mais frequente nas crianças mais velhas. A situação de produção de desenho antes da escrita favoreceu uma narrativa mais elaborada, com explicação causal e desfecho elaborado nas narrativas das crianças de 7 anos e, também, resolução da situação problema explicada nas narrativas das crianças de 9 anos. De acordo com Lins e Silva e Spinillo (2000), os textos narrativos escritos mais elaboradas de crianças do $2^{\circ}$ ao $5^{\circ}$ ano foram construídos a partir de sequências de gravuras ou de histórias ouvidas.

A escrita de textos envolve, assim, uma complexa inter-relação entre habilidades e saberes de natureza linguístico-cognitiva (Ferreira \& Correa, 2008). Embora não seja um requisito suficiente para a produção textual, a escrita de palavras é, no entanto, uma competência necessária para a elaboração do texto escrito (Abbott \& Berninger, 1993; Correa \& Dockell, 2007). A escrita de palavras implica o conhecimento do princípio alfabético, como o aprendizado das convenções ortográficas.
Dificuldades com a acurácia e a fluência na escrita de palavras dificultam a produção de um texto, uma vez que a grafia das palavras requer demais dos recursos cognitivos que poderiam ser destinados à composição do texto e ao estabelecimento de sua inteligibilidade, ou seja, da coerência (Correa, 2010; Gregg \& Mather, 2002). O tempo e os recursos cognitivos empregados no estabelecimento das correspondências grafofonêmicas e das convenções ortográficas não automatizadas pelas crianças propiciam o esquecimento da proposição que se segue ou que se seguiu imediatamente àquela que está sendo escrita, tendo como consequência a descontinuidade do texto (Berninger et al., 2002; Graham \& Harris, 2000; Gregg \& Mather, 2002).

As dificuldades no domínio das correspondências fonografêmicas e das convenções ortográficas tem ainda implicações negativas no que diz respeito à motivação para escrever (Correa \& MacLean, 1999). Por conta da dificuldade, do esforço despendido e da falta de sucesso, as crianças passam a não gostar de escrever e, tanto quanto possível, encontram uma desculpa para não fazê-lo (Bruning \& Horn, 2000). Ademais, um texto escrito com uma série de transgressões ortográficas é uma evidência das dificuldades da criança, o que muitas vezes a deixa constrangida na presença dos pares e da professora (Correa $\&$ MacLean, 1999). Assim, a criança se esquiva sempre que uma atividade de escrita é proposta, o que a afasta mais ainda da possibilidade de progredir nesta habilidade.

A produção escrita de textos, atividade criativa que se caracteriza por ser um processo aberto, não completamente especificado e falível, inclui três atividades principais, que são cíclicas e interativas: planejamento, escrita e revisão (Sharples, 1999). Tais atividades, apesar de nomeadas em sequência, são realizadas e integradas durante 0 ato da produção escrita, retroalimentando-se.

Neste sentido, a preocupação com o domínio do princípio alfabético e o aprendizado das convenções ortográficas para a produção de texto deve ser estendida também para a leitura de palavras e de textos. A leitura está implicada no ato da escrita (Ehri, 1997). Não há como proceder à revisão ou planejar a continuidade da escrita sem ler o que já foi escrito. Assim, o desenvolvimento da habilidade de leitura, tanto quanto da escrita de palavras, é um requisito necessário à produção de texto. A leitura é, ainda, uma forma de desenvolver as habilidades necessárias à proficiência na produção textual escrita, como dos conhecimentos adquiridos por esta via, tanto em termos de conteúdo (o que escrever), quanto da forma (como escrever).

O reconhecimento de palavras, de como escrever palavras, pode ocorrer pelo uso da estratégia fonológica ou pelo acesso ao léxico ortográfico. A funcionalidade da estratégia fonológica pode ser inferida especialmente pela habilidade de ler ou de escrever pseudopalavras, enquanto o acesso ao léxico ortográfico é demonstrado principalmente pelo desempenho na leitura, ou pela escrita, de palavras irregulares (Salles \& Parente, 2007).

As pseudopalavras são construídas com padrões grafofonêmicos sancionados pela língua, o que permite que 
possam ser lidas ou mesmo escritas segundo o conhecimento das convenções da linguagem escrita do falante. As pseudopalvras, porém, não possuem significado. Assim, sem poder recorrer ao significado como estratégia para auxiliar na decodificação ou na codificação, o falante deverá utilizar seu conhecimento acerca das correspondências grafofonêmicas ou fonografêmica para, respectivamente, a leitura ou a escrita das pseudopalavras. Pelo emprego de estratégias fonológicas, as crianças podem ler ou escrever palavras pouco frequentes ou mesmo desconhecidas. A leitura ou a escrita fluentes exigem precisão e automatismo no reconhecimento de palavras, requerendo maior uso do acesso ao léxico ortográfico mental, ou seja, ao conjunto das representações ortográficas das palavras de uma língua automatizadas pelo leitor.

O objetivo do presente trabalho é examinar a produção escrita de textos narrativos em crianças do $3^{\circ}$ ano, ou seja, do final do $1^{\circ}$ ciclo do Ensino Fundamental, relacionando-a ao perfil de leitura e de escrita de palavras e de pseudopalavras destas crianças. Autores como Lins e Silva e Spinillo (1998, 2000), Spinillo (2001) e Brandão e Spinillo (2001) propuseram uma série de categorias para classificar as produções textuais de textos narrativos por crianças, incluindo a presença ou a ausência de introdução da cena (tempo e lugar); personagens com metas a serem alcançadas; eventos; situação-problema; resolução da situação-problema; e fechamento (Spinillo, 2001). Esta classificação tem como referência a Gramática de Histórias, um tipo de análise estrutural de narrativas, caracterizada por um conjunto formal de regras que descrevem a formação de histórias como algo previsível. Tal sistema de análise (Spinillo, 2001) foi adaptado e utilizado no presente estudo para a avaliação da produção textual das crianças.

\section{Método}

\section{Participantes}

Participaram deste estudo 93 crianças do $3^{\circ}$ ano (na época da avaliação: $2^{\mathrm{a}}$ série) do Ensino Fundamental de cinco escolas públicas do estado do Rio Grande do Sul (Brasil), com idade média de 8 anos e 3 meses (desvio padrão de 4 meses), sendo 49 meninas e 44 meninos.

\section{Tarefas}

a) Leitura de palavras

Avalia a precisão na leitura oral de palavras (e pseudopalavras) isoladas, que variam em suas características psicolinguísticas de regularidade (estímulos regulares e irregulares), lexicalidade (palavras e pseudopalavras), extensão (estímulos curtos e longos) e frequência de ocorrência na língua (palavras frequentes e não frequentes). O instrumento consiste de 60 estímulos (Salles \& Parente, 2002, 2007, 2008; Salles, Freitas, \& Parente, 2010), sendo 20 de cada categoria (palavras regulares, irregulares e pseudopalavras). Os estímulos foram apresentados aleatoriamente, de forma individual, em fichas, e os participantes foram orientados a lê-los em voz alta. Os resultados são expostos em termos de número ou porcentagem de acertos no total da tarefa e em cada categoria de estímulos.

b) Escrita de palavras sob ditado

A tarefa foi retirada do Teste de Desempenho Cognitivo-Linguístico - TDCL (Capellini \& Smythe, 2008), adaptado do International Dyslexia Test - parte coletiva (Capovilla, Smythe, Capovilla, \& Everatt, 2001; Smythe \& Everatt, 2000), e consiste em 40 estímulos (30 palavras e 10 pseudopalavras) que variam em suas características psicolinguísticas de lexicalidade (palavras e pseudopalavras), regularidade (palavras regulares, irregulares e regra) e extensão. Os estímulos curtos são dissilábicos de até cinco letras, enquanto os longos são trissilábicos e polissilábicos, contendo seis ou mais letras. Dentre as palavras, 16 são irregulares, seis são regulares e oito são do tipo regra; sendo 18 longas e 12 curtas. Os escores são expostos em porcentagem de acertos em cada categoria de estímulos. Segundo a lista de frequência de ocorrência de palavras expostas a crianças de $2^{\mathrm{a}}$ série, de Pinheiro (1996), 24 das palavras são de baixa frequência e seis são frequentes.

c) Produção escrita de texto

As crianças foram avaliadas em uma sessão coletiva para a escrita de textos (Salles, 2005) e de palavras. Nesta avaliação da escrita, solicitou-se às crianças que escrevessem uma história a partir de sequências de gravuras, retiradas do item "Fogo" do subteste Arranjo de Figuras do WISC (Weschsler Intelligence Scale for Children, Weschsler, 1949), uma vez que Lins e Silva e Spinillo (2000) concluíram que os textos narrativos escritos mais elaboradas de crianças de $1^{\mathrm{a}}$ a $4^{\mathrm{a}}$ série foram construídos a partir de sequências de gravuras ou de histórias ouvidas.

As histórias produzidas foram analisadas independentemente por dois juízes e enquadradas em uma das cinco categorias, apresentadas a seguir, adaptadas de Lins e Silva e Spinillo (1998, 2000), Spinillo (2001) e Brandão e Spinillo (2001). O índice de concordância entre juízes (Teste W de Kendall) na categorização da produção escrita de história foi $0,88(p<0,01)$. As categorias enfatizam a organização textual, relações entre os enunciados e relações entre a história e o tema sugerido nas gravuras, assim como a presença dos elementos cruciais para a constituição de uma história.

\section{Categoria I}

Textos que consistem de frases soltas, que podem ou não estar relacionadas ao tema. Inclui também produções que se caracterizam por tentativas de início de história (era uma vez...), porém sem continuidade. 


\section{Exemplo 1.}

TGORIESTAUARII AMDOCNMFO

Tradução (com tentativas de corrigir o texto em itálico): O gori (guri) estava brincamdo (brincando) com fogo.

\section{Exemplo 2.}

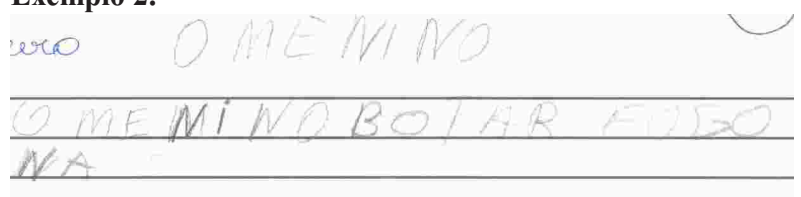

Tradução (com tentativas de corrigir o texto em itálico):

$\mathrm{O}$ menino

O memino (menino) botar fogo na

\section{Categoria II}

Produções caracterizadas pela descrição de estados de personagens ou de eventos em uma sequência de ações, sem que sejam explicitadas as relações causais entre os enunciados. O problema não está explicitado. A seguir está um exemplo escrito por uma menina de 8 anos.

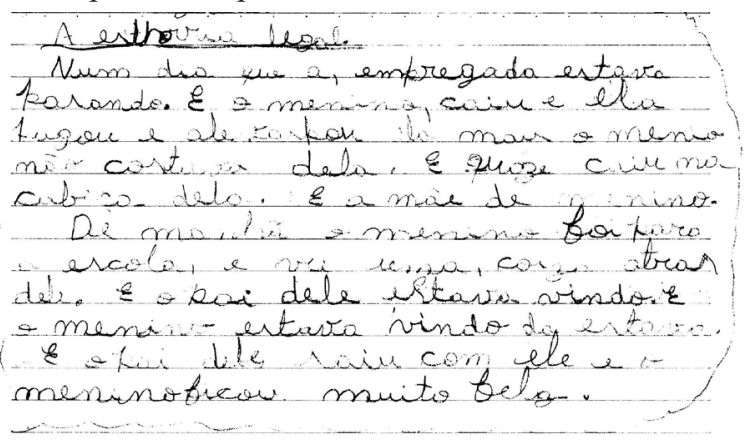

Tradução (com tentativas de corrigir o texto em itálico):

A esthorria (estória) legal

Num dia que a, empregada estava pasando (passando). E o menino, caiu e ela (ele) pagou (pegou) e ale (ele) raspou ela mais (mas) o menino não costava (gostava) dela e quaze (quase) caiu na cabeça dela. E a mae de menino. De manha o menino foi para a escola, e viu uma coiza (coisa) atrás dele. E o pai dele estava vindo. E o menino estava vindo da estava (escola). E o pai dele saiu com ele e o menino ficou muito feliz.

\section{Categoria III}

Semelhante à categoria anterior, apresentando ainda uma ação que sugere o esboço de uma situação-problema e da resolução do problema. O desfecho (consequência) está ausente. Esta categoria também engloba produções nas quais a resolução está ausente, mas há um esboço de desfecho (Ex.: "chegaram os bombeiros e viveram felizes para sempre"). A seguir apresenta-se um exemplo de história escrita por um menino de 8 anos.

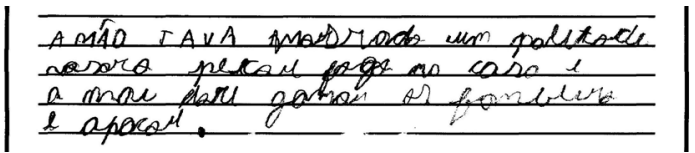

Tradução (com tentativas de corrigir o texto em itálico):

A mao (seria mãe) tava amasrado (segurando) um palitode (palito de) sosoro (fosforo) pecou (pegou) fogo na casa e a mae dare (dai) gamou (chamou) os bonbero (bombeiros) e apacou (apagou).

\section{Categoria IV}

Semelhante à categoria anterior, apresentando também tentativa(s) de resolução da situação-problema. O desfecho está presente, porém não é explicitado como a situação-problema foi resolvida. $\mathrm{O}$ desfecho é repentino e pouco elaborado. A seguir está um exemplo de história produzida por uma menina de 8 anos.

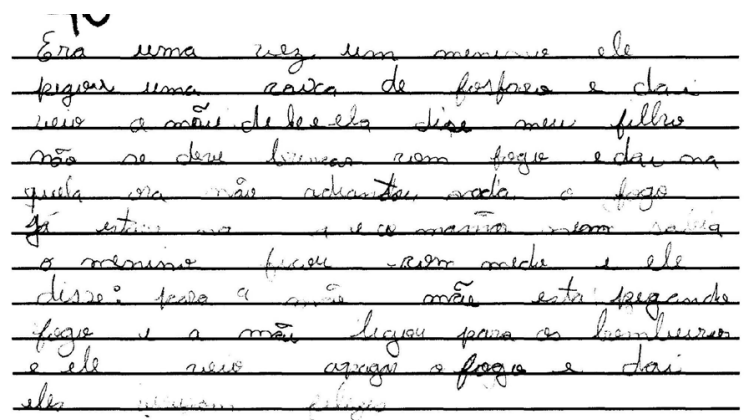

Tradução (com tentativas de corrigir o texto em itálico): Era uma vez um menino ele pegou uma caixa de fosforo e dai veio a mãe dele e ela dise (disse) meu filho não se deve brincar com fogo e dai na quela (naquela) ora (hora) não adiantou nada o fogo já na estava na a e co (cortina $\left.{ }^{2}\right)$ mamãe nem sabia o menino ficou com medo e ele disse: para a mãe mãe esta pegando fogo e mãe ligou para os bombeiros e ele veio apagou o fogo e dai eles viveram felizes.

\section{Categoria V}

Histórias completas com uma estrutura narrativa elaborada, em que o desfecho da trama é explicitado. Podem surgir novos personagens e problemas além daquele sugerido pelas gravuras. Maior elaboração na passagem do estado inicial para o estado final, explicitando-se os meios de resolução da situação-problema.

Exemplo: Menina de oito anos

A casa que pegou fogo

Era uma vez uma casa que, lá morava uma mulher.

Com seu filho Andrei ele, pegou um frosto e riscou.

Quando ele riscou, ele botou no chão e pegou fogo na casa.

Ele saiu pra fora e chamou os bombeiros, para apagar o fogo.

Os bombeiros vieram e apagaram o fogo.

E ninguém ficou ferido, mais o Andrei aprendeu que não deve brincar com fogo.

2 Infere-se por conta da figura apresentada 


\section{Procedimentos gerais}

Após contato com as escolas selecionadas, o Termo de Consentimento Livre e Esclarecido foi enviado aos pais/responsáveis. As crianças autorizadas a participar foram avaliadas em uma sessão coletiva (escrita de palavras isoladas e de texto) e em uma sessão individual (leitura de palavras isoladas). O projeto de pesquisa foi aprovado pelo Comitê de Ética em Pesquisa da Universidade Federal do Rio Grande do Sul (cadastro número 229).

\section{Resultados}

Inicialmente, a produção textual escrita das crianças foi analisada de forma descritiva, tendo como base a classificação proposta por Lins e Silva e Spinilo $(1998,2000)$. O resultado de tal análise é apresentado em termos da porcentagem de textos (crianças) classificados em cada uma das categorias da avaliação realizada. Em seguida, procedeu-se às análises visando o estabelecimento dos diferentes perfis de leitura e de escrita de palavras e pseudopalavras por meio da Análise de Agrupamentos (Cluster Analysis), associando os perfis encontrados à variabilidade observada na produção textual de histórias.

\section{A produção de histórias escritas}

A Tabela 1 apresenta a distribuição da produção textual segundo a complexidade estrutural das narrativas escritas pelas crianças. Das histórias escritas pelas crianças, 49\% delas (Categorias IV e V) foram organizadas segundo a estrutura narrativa prototípica, incluindo, portanto, o início da história, o desenvolvimento da trama e o seu final. No entanto, em apenas $16 \%$ das histórias observou-se a existência de mais detalhes e de transição mais elaborada entre as partes constituintes da narrativa (Categoria $\mathrm{V}$ ). Por outro lado, $28 \%$ das histórias escritas possuíam uma estrutura narrativa bastante elementar, não ultrapassando a categoria II de produção de histórias. Segundo a Tabela 1, $51 \%$ das histórias produzidas pelas crianças no $3^{\circ}$ ano não incluíam um desfecho (Categorias I, II e III).

Tabela 1

Distribuição das histórias (número e porcentagem) segundo a complexidade de sua organização narrativa

\begin{tabular}{ccc}
\hline & \multicolumn{2}{c}{ Produção escrita de história } \\
\cline { 2 - 3 } & $\mathbf{N}^{\mathbf{0}}$ & Porcentagem \\
\hline Categoria I & 12 & 13 \\
Categoria II & 14 & 15 \\
Categoria III & 21 & 23 \\
Categoria IV & 31 & 33 \\
Categoria V & 15 & 16 \\
\hline
\end{tabular}

\section{A produção de histórias escritas e a habilidade de leitura de palavras e pseudopalavras}

A Análise de Variância mostra que a porcentagem de palavras regulares $(M=91,50 ; \mathrm{DP}=10,47)$, irregulares $(\mathrm{M}=80,85 ; \mathrm{DP}=12,73)$ e pseudopalavras $(\mathrm{M}=70,58$; $\mathrm{DP}$ $=17,27)$ lidas acuradamente pelas crianças varia significativamente segundo o tipo de estímulo apresentado ( $\mathrm{F}$ $(2,184)=94,76, p<.01)$. A comparação entre as médias (Bonferroni) revela que as palavras regulares foram lidas com mais facilidade pelas crianças. O maior grau de dificuldade ficou por conta da leitura de pseudopalavras.

\section{Leitura de palavras regulares e pseudopalavras}

De forma a estabelecer perfis diferenciados na habilidade de leitura de palavras e pseudopalavras, foram realizadas duas Análises de Agrupamentos (Cluster Analysis). A escolha de palavras regulares e de pseudopalavras como parâmetros para a realização das análises deve-se à possibilidade de emprego, pela criança, da estratégia fonológica de leitura. No caso de palavras irregulares, a única estratégia de leitura possível seria a memorização. A primeira análise visou estabelecer diferenças na habilidade de leitura das crianças de palavras regulares e de pseudopalavras e resultou em três grupos, conforme mostra a Tabela 2.

\section{Tabela 2}

Desempenho (média e desvio-padrão) de leitura de palavras Regulares e de pseudopalavras (em \% de acertos)

\begin{tabular}{ccccc}
\hline & \multicolumn{2}{c}{$\begin{array}{c}\text { Palavras } \\
\text { regulares }\end{array}$} & \multicolumn{2}{c}{ Pseudopalavras } \\
\hline Subgrupos & M & DP & M & DP \\
\hline $\begin{array}{c}\text { Grupo 1 - bons leitores } \\
\text { na estratégia fonológica } \\
\text { (n=38) }\end{array}$ & 93,03 & 5,76 & 77,50 & 5,034 \\
\hline $\begin{array}{c}\text { Grupo 2 - leitores } \\
\text { médios na estratégia } \\
\text { fonológica (n=17) }\end{array}$ & 75,00 & 12,62 & 63,23 & 12,11 \\
\hline $\begin{array}{c}\text { Grupo 3 - leitores } \\
\text { proficientes na } \\
\text { estratégia fonológica } \\
(\mathrm{n}=38)\end{array}$ & 97,37 & 0,78 & 92,08 & 5,56 \\
\hline
\end{tabular}

O Grupo 1 inclui as crianças que tem um bom conhecimento das correspondências grafofonêmicas regulares, como um bom uso da estratégia fonológica para a leitura. Por outro lado, no Grupo 2, as crianças possuem bom desempenho na leitura de palavras regulares, mas um desempenho mediano ao empregar uma estratégia puramente fonológica de leitura. Finalmente, o Grupo 3 reúne crianças habilidosas tanto na leitura de palavras regulares como no uso da estratégia fonológica. 
Em seguida, os perfis de leitura resultantes da Análise de Agrupamentos foram associados à produção textual das crianças. Esta análise objetivou examinar a habilidade das crianças produzirem textos em função do conhecimento que estas têm das regularidades grafofonêmicas do Português, como o uso de uma estratégia fonológica de leitura, expressa pela leitura de pseudopalavras. A Tabela 3 mostra a produção textual dos três grupos resultantes da Análise de Aglomerados segundo a habilidade de leitura de palavras regulares e de pseudopalavras.

Tabela 3

Distribuição da amostra (frequência e \% de casos) nas categorias de produção textual segundo os perfis de leitura de palavras regulares e de pseudopalavras

\begin{tabular}{ccccccc}
\hline & & \multicolumn{5}{c}{ Categorias de produção } \\
\cline { 3 - 7 } & & I & II & III & IV & V \\
\hline \multirow{2}{*}{ Grupo 1 } & Frequência & 2 & 6 & 9 & 17 & 4 \\
bons leitores & $\%$ & 5 & 16 & 24 & 45 & 10 \\
& Resíduos & $-1,3$ & 0,1 & 0,1 & 1,2 & $-0,9$ \\
\hline \multirow{2}{*}{ Grupo 2 } & Frequência & 5 & 4 & 3 & 5 & 0 \\
leitores médios & $\%$ & 29 & 24 & 8 & 29 & 0 \\
& Resíduos & 1,9 & 0,9 & $-0,4$ & $-0,3$ & $-1,7$ \\
\hline Grupo 3 & Frequência & 5 & 4 & 9 & 9 & 11 \\
leitores & $\%$ & 13 & 10 & 24 & 24 & 29 \\
habilidosos & Resíduos & 0 & $-0,7$ & 0,1 & -1 & 2 \\
\hline
\end{tabular}

As diferenças significativas entre os diferentes perfis $\left(\mathrm{x}^{2}(8, \mathrm{~N}=93)=16,85, \mathrm{p}=.03\right)$ podem ser assim resumidas, procedendo-se a análise de resíduos padronizados: a) $\mathrm{O}$ grupo de leitores habilidosos (Grupo 3) tende a produzir mais histórias classificadas na categoria $\mathrm{V}$, enquanto havia crianças que, apesar da boa leitura de palavras regulares, apresentaram relativa dificuldade no emprego de estratégia fonológica na leitura (Grupo 2) não produziram qualquer história com maior nível de complexidade (categoria V); b) As crianças do Grupo 2 por outro lado, produziram, de forma expressiva, mais histórias elementares (categoria I).

Os resultados descritos acima mostram que a escrita de histórias mais complexas do ponto de vista de sua estrutura narrativa parece estar associada ao conhecimento das regularidades da língua e também ao uso hábil da estratégia fonológica na leitura.

\section{Leitura de palavras irregulares}

Esta segunda análise visou estabelecer se a complexidade estrutural do texto escrito produzido pelas crianças poderia variar com o conhecimento acerca das irregularidades do sistema ortográfico. A habilidade de leitura das palavras irregulares é um indicador do desenvolvimento do léxico ortográfico.

Dois grupos foram formados quando reagrupamos as crianças realizando uma Análise de Agrupamentos para a habilidade de leitura de palavras irregulares. De acordo com a Tabela 4, observa-se que o Grupo 1 revela um conhecimento precário (regular) para as irregularidades da língua, enquanto o Grupo 2 mostrou-se hábil na leitura de palavras irregulares.

Tabela 4

Desempenho (média e desvio-padrão) de leitura de palavras irregulares (em \% de acertos)

\begin{tabular}{lcc}
\hline & \multicolumn{2}{c}{ Palavras irregulares } \\
\cline { 2 - 3 } & $\mathbf{M}$ & $\mathbf{D P}$ \\
\hline Grupo 1 - não proficiente $(\mathrm{n}=51)$ & 58,25 & 12,09 \\
\hline Grupo 2 - proficiente $(\mathrm{n}=42)$ & 85,55 & 8,50 \\
\hline
\end{tabular}

A associação entre os perfis de leitura de irregularidades, a produção textual das crianças $\left(\mathrm{x}^{2}(8, \mathrm{~N}=93)=13,79\right.$, $\mathrm{p}=.008)$ e a análise de resíduos revelam que os Grupos 1 e 2 diferem de forma expressiva na porcentagem de histórias de nível V, de estrutura narrativa mais complexa. As crianças do Grupo 2 tendem a produzir mais histórias que foram classificadas neste nível. As crianças que são leitoras mais habilidosas (Grupo 2) tiveram 57\% das narrativas classificadas nas categorias IV e V. Grupos 1 e 2 diferem de forma expressiva quanto ao número de histórias elementares que produzem, sendo menor a sua ocorrência no Grupo 2.

Tabela 5

Distribuição das histórias (frequência e \% de casos) nas categorias de produção textual segundo os perfis de leitura de palavras irregulares

Categorias de produção textual

\begin{tabular}{lcccccc} 
& \multicolumn{7}{c}{ I } & II & III & IV & V & \\
\cline { 2 - 7 } Frequência & 10 & 10 & 13 & 15 & 3 & \\
\hline Grupo 1 - não & $\%$ & 20 & 20 & 25 & 29 & 6 \\
\cline { 2 - 7 } proficiente & Resíduo & 1,3 & 0,8 & 0,4 & $-0,5$ & $-1,8$ \\
\hline \multirow{2}{*}{$\begin{array}{l}\text { Grupo 2 }- \\
\text { proficiente }\end{array}$} & Frequência & 2 & 4 & 8 & 16 & 12 \\
\cline { 2 - 7 } & $\%$ & 5 & 9 & 19 & 38 & 29 \\
& Resíduo & $-1,5$ & $-0,9$ & $-0,5$ & 0,5 & 2 \\
\hline
\end{tabular}

O conjunto de nossos resultados sugerem a importância das habilidades fonológicas de decodificação. Com a automatização da estratégia fonológica de leitura e a 
consequente liberação de recursos cognitivos para a compreensão leitora, é possível que a leitura, menos laboriosa, torne-se mais prazerosa para a criança. Como consequência, a criança, mais motivada e mais competente, leria mais, e com mais experiência em leitura, teria maior conhecimento de palavras irregulares e da própria estrutura narrativa de histórias. Uma vez que as crianças proficientes fonológica e ortograficamente tendem a produzir historias nos níveis $\mathrm{lV}$ e $\mathrm{V}$, e como a frequência de proficiência em ambas as habilidades é muito semelhante, é provável que sejam as mesmas crianças. Neste caso, retirada a variabilidade devida à leitura de palavras regulares e pseudopalavras, a leitura de palavras irregulares permaneceria, ainda sim, associada à proficiência na escrita de histórias.

Para testar tal hipótese foi realizada uma Análise de Regressão Múltipla, tendo como variável dependente a escrita controlando o efeito. A leitura de palavras irregulares $(\beta=0,24, p=0,05)$ teve contribuição independente para a escrita $\left(R^{2}=0,151, F(3,92)=5,30 p=0,002\right)$, uma vez retirada a variabilidade atribuída à leitura de palavras e pseudopalavras.

\section{A produção de histórias escritas e a habilidade de escrita de palavras e pseudopalavras}

De forma similar à análise realizada para o desenvolvimento das habilidades de leitura, a Análise de Variância mostrou que a habilidade de escrita também varia de acordo com o tipo de estímulo apresentado $(\mathrm{F}(2,184)=41,78, \mathrm{p}<0.01)$. Conforme apresentado anteriormente por Salles e Parente (2007), a comparação entre os pares de média (Bonferroni) revela que a escrita de palavras regulares $(\mathrm{M}=89,43 ; \mathrm{DP}=17,85)$ é mais fácil do que a da escrita de pseudopalavras $(M=71,29$; $\mathrm{DP}=21,01)$, e a escrita destas, por sua vez, mais fácil do que a escrita de palavras irregulares ( $M=44,97$; DP 17,56).

\section{Escrita de Palavras Regulares e Pseudopalavras}

O estabelecimento de diferentes perfis na habilidade de escrita de palavras regulares e pseudopalavras e sua associação com a produção de histórias teve como objetivo avaliar a variabilidade da narrativa escrita e os conhecimentos das correspondências regulares na escrita como do emprego de estratégia fonológica por meio do ditado de pseudopalavras. Novamente, a escolha de palavras regulares e de pseudopalavras como parâmetros para a realização das análises deve-se à possibilidade de emprego pela criança da estratégia fonológica, desta feita, para a sua escrita. No caso de palavras irregulares, a única estratégia de escrita possível seria pela memorização de suas grafias (estratégia ortográfica). Os perfis originados pela Análise de Agrupamentos para a escrita de palavras regulares e pseudopalavras é apresentado na Tabela 6. O Grupo 1 apresenta um excelente conhecimento grafofonêmico regular, e também é hábil no emprego de uma estratégia fonológica ao escrever. Por sua vez, o Grupo 2 mostra um desempenho regular no domínio das regularidades grafofonêmicas e apresenta dificuldades na codificação.

\section{Tabela 6}

Desempenho (média e desvio-padrão) de escrita de palavras regulares e de pseudopalavras

\begin{tabular}{ccccc}
\hline & \multicolumn{2}{c}{$\begin{array}{c}\text { Ditado } \\
\text { Palavras } \\
\text { regulares }\end{array}$} & \multicolumn{2}{c}{$\begin{array}{c}\text { Ditado } \\
\text { Pseudopalavras }\end{array}$} \\
\cline { 2 - 5 } & $\mathrm{M}$ & $\mathrm{DP}$ & $\mathrm{M}$ & $\mathrm{DP}$ \\
\hline $\begin{array}{c}\text { Grupo 1 - escrita } \\
\text { proficiente (n=75) }\end{array}$ & 95,78 & 8,70 & 77,73 & 15,47 \\
\hline $\begin{array}{c}\text { Grupo 2 - escrita não } \\
\text { proficiente (n=18) }\end{array}$ & 62,98 & 21,81 & 44,44 & 20,06 \\
\hline
\end{tabular}

Quanto à produção textual destes dois grupos, observa-se uma associação significativa entre a escrita de palavras regulares e pseudopalavras (uso de conhecimentos fonografêmicos) e a complexidade da narrativa escrita pelas crianças $\left(\mathrm{x}^{2}(8, \mathrm{~N}=93)=23,11, \mathrm{p}=.00\right)$. Pela Tabela 7 vêse que no grupo de crianças pouco habilidosas na escrita de palavras regulares e pseudopalavras há uma ocorrência expressiva de histórias de nível I (nível mais elementar) e menos histórias com estruturas narrativas mais elaboradas (Nível IV) do que o Grupo 2. São expressivas, ainda, a frequência de histórias de nível II e a ausência de histórias de Nível V.

\section{Tabela 7}

Distribuição da amostra (frequência e \% de casos) nas categorias de produção textual segundo os perfis de escrita de palavras regulares e de pseudopalavras

\begin{tabular}{ccccccc}
\hline & & \multicolumn{5}{c}{ Categorias de produção } \\
textual
\end{tabular}

\section{Escrita de Palavras Irregulares}

Quando refazemos os agrupamentos tendo como critério o desempenho das crianças na escrita de palavras irregulares, observa-se que pela Análise de Agrupamentos resultam três grupos (Tabela 8): um grupo de escritores com uma boa habilidade de escrita de palavras irregulares (Grupo 1); um segundo grupo com dificuldades na escrita destas palavras (Grupo 2); e um terceiro grupo com conhecimento de escrita de poucas palavras irregulares (Grupo 3). 
Tabela 8

Desempenho (média e desvio-padrão) de escrita de palavras irregulares (\% de acertos)

\begin{tabular}{ccc}
\hline & \multicolumn{2}{c}{$\begin{array}{c}\text { Ditado } \\
\text { Palavras } \\
\text { irregulares }\end{array}$} \\
\hline & $\mathrm{M}$ & $\mathrm{DP}$ \\
\hline Grupo 1 - escrita ortográfica boa (n=33) & 63,26 & 7,29 \\
\hline Grupo 2 - escrita ortográfica mediana ( $\mathrm{n}=43)$ & 41,59 & 7,17 \\
\hline Grupo 3 - escrita ortográfica não proficiente & 18,01 & 6,20 \\
\hline$(\mathrm{n}=17)$ & & \\
\hline
\end{tabular}

A avaliação da produção escrita destas crianças pode ser vista na Tabela 9. Esta análise objetivou examinar a associação entre a variabilidade observada na produção textual e sua associação ao conhecimento das regularidades ortográficas pelas crianças. Tal associação não se mostrou significativa $\left(\mathrm{x}^{2}(8, \mathrm{~N}=93)=12,25, \mathrm{p}=.14\right)$.

Tabela 9

Distribuição das histórias (frequência e \% de casos) nas categorias de produção textual segundo os perfis de escrita de palavras irregulares

\begin{tabular}{ccccccc}
\hline & \multicolumn{6}{c}{ Categorias de produção textual } \\
\hline & I & II & III & IV & V \\
\hline \multirow{2}{*}{$\begin{array}{c}\text { Grupo } \\
1-\text { escrita } \\
\text { ortográfica } \\
\text { boa }\end{array}$} & Frequência & 2 & 3 & 8 & 13 & 7 \\
\cline { 2 - 7 } & Resíduo & $-1,1$ & 0,9 & 0,2 & 0,6 & 0,7 \\
\hline $\begin{array}{c}\text { Grupo } \\
2-\text { escrita } \\
\text { ortográfica } \\
\text { mediana }\end{array}$ & Frequência & 5 & 7 & 8 & 15 & 8 \\
\cline { 2 - 7 } & Resíduo & 0,2 & 0,2 & $-0,5$ & 0,2 &, 4 \\
\hline $\begin{array}{c}\text { Grupo } \\
3-\text { escrita } \\
\text { ortográfica } \\
\text { não }\end{array}$ & Frequência & 5 & 4 & 5 & 3 & 0 \\
\cline { 2 - 7 } proficiente & Resíduo &, 9 & 0,9 & 0,6 & $-1,1$ & $-1,7$ \\
\hline
\end{tabular}

Pela análise dos residuais, observa-se que não houve diferença expressiva no desempenho dos Grupos 1 e 2 na produção textual no que se refere ao nível de organização da trama. Crianças com dificuldades na escrita de palavras podem ser capazes de escrever histórias com maior nível de coerência (52\% das histórias nas Categorias IV e V). Por outro lado, o Grupo 3, composto de crianças com conhecimento bastante rudimentar das irregularidades do sistema ortográfico produziu uma percentagem expressiva de histórias em nível elementar de organização narrativa (categorias I e II). Nota-se também neste grupo um número expressivamente reduzido de narrativas com maior nível de complexidade, $17 \%$ das histórias na Categoria IV e nenhuma história na categoria $\mathrm{V}$.

\section{Discussão}

Leitura e escrita são habilidades complexas e multivariadas, envolvendo fatores de natureza linguística, cognitiva e sociocultural. O presente trabalho circunscreve-se ao exame dos aspectos linguístico-cognitivos associados ao desenvolvimento da linguagem escrita. Objetivou-se descrever a produção escrita de textos narrativos de crianças cursando o final do $1^{\circ}$ Ciclo do Ensino Fundamental, relacionando-a ao perfil de leitura e de escrita de palavras e de pseudopalavras destas crianças. Foram avaliadas as histórias escritas por crianças no $3^{\circ}$ ano (ano que encerra o ciclo de ensino fundamental iniciado com a alfabetização) segundo o nível de complexidade narrativa. Observouse variabilidade importante no desempenho na produção escrita de textos (histórias) das crianças, apesar de todas frequentarem a mesma série escolar. De forma geral, as crianças puderam ser divididas em três grupos, segundo as características das histórias produzidas: (1) as que apresentaram uma produção escrita bastante elementar (categoria I); (2) as que produziram histórias incompletas (categorias II e III), padrão que caracterizou grande parte das produções; e (3) as que produziram histórias completas (categoria IV e V). A produção de pouco mais da metade das histórias escritas caracterizou-se pela ausência de uma situação-problema (categorias I e II) ou por apenas um esboço desta (categoria III). As produções que incluíam um problema e sua resolução foram, na grande maioria, muito descritivas, apesar de conterem os elementos principais de uma narrativa (categoria IV). Não se pode afirmar, no entanto, que as crianças que estão no grupo 1 (categoria I) apresentem dificuldades no aprendizado da escrita. Muitas crianças habilidosas escrevem histórias elementares simplesmente por fatores motivacionais: não estavam com vontade de escrever ou não gostam de escrever.

Estudando a produção escrita de histórias, Lins e Silva e Spinillo (1998) referem que tanto em crianças de classe média alta (escolas particulares) quanto nas de baixa renda (escolas públicas) é pouco frequente a escrita de histórias bem elaboradas logo após a alfabetização. Este tipo de produção só ocorreria passados alguns anos de escolaridade após a alfabetização. Os progressos observados entre as crianças de classe média alta foram mais expressivos, sendo estas diferenças interpretadas por fatores sociolinguísticos, como contato com textos no ambiente familiar. O domínio da estrutura narrativa, concluem Lins e Silva e Spinillo (2000), não depende apenas de fatores como idade e escolaridade, mas é influenciado também pela exposição e contato que as crianças têm com textos.

Contudo, no estudo de Lins e Silva e Spinillo (1998), a frequência das crianças do $3^{\circ}$ ano de escolas públicas nas 
categorias de produção escrita mais elementares (I e II) foi maior do que a encontrada no presente estudo. Em Lins e Silva e Spinillo (1998) 70\% das crianças estavam enquadradas nas categorias mais baixas, contra apenas 31,5\% das crianças do presente estudo (somando-se a amostra que atingiu as categorias I e II). Nenhuma produção escrita do estudo de Lins e Silva e Spinillo (1998) foi avaliada na categoria $\mathrm{V}$, enquanto $15 \%$ das crianças em nosso estudo produziu histórias com estruturas narrativas mais elaboradas. Em ambos os estudos, porém, a maioria das crianças produziu histórias incompletas, sem a presença de um desfecho para a narrativa. As crianças do presente estudo são, na maioria, de classe média baixa, todas provenientes de escolas públicas estaduais. As diferenças entre os resultados alcançados por Lins e Silva e Spinillo (2000) e os do presente estudo podem ser resultantes de diferentes práticas de letramento.

As diferenças encontradas podem ser também de cunho metodológico. No estudo de Lins e Silva e Spinillo (1998) as crianças deveriam escrever uma história original, sem sugestão de tema. É possível que fornecer pista visual (sequência de figuras), como no presente estudo, proporcione um apoio para a produção do texto. Além disso, apesar de critérios semelhantes adotados na avaliação das histórias em categorias e a presença de juízes independentes, a avaliação das histórias não é objetiva. Em relação à forma de aplicação da tarefa de escrita, era parcialmente livre, apenas baseada nas imagens, permitindo à criança criar uma história. Na correção desta tarefa, privilegiou-se a estrutura em detrimento do conteúdo da história. Portanto, para a criança atingir a categoria V na escrita bastava produzir uma história que incluísse todos os elementos estruturais esperados, mesmo que esta tenha sido pouco elaborada.

Conforme Ferreira e Correa (2008), a variabilidade da produção de histórias, em termos de complexidade narrativa, por crianças de mesma série/idade sugere que outros fatores além da idade, escolaridade e contexto de produção influenciam a escrita de histórias pelas crianças. Um dos fatores investigados em nosso estudo foram as habilidades de leitura e escrita de palavras, objetivando examinar a associação entre tais habilidades e as diferenças observadas na produção textual das crianças no $3^{\circ}$ ano.

Analisando-se a escrita de histórias em função dos diferentes perfis de habilidades de leitura e escrita de palavras e pseudopalavras apresentados pelas crianças, percebe-se que estas habilidades e a produção de texto narrativo escrito estão diretamente relacionadas. De forma esperada, crianças que são hábeis na leitura e escrita de palavras regulares também são hábeis na produção escrita de textos. O inverso também foi verdadeiro, dificuldades no nível da palavra parecem ser acompanhadas de dificuldades no nível do texto. A mesma associação pode ser feita entre a habilidade de leitura e de escrita de pseudopalavras pelas crianças e a produção escrita de narrativas. Neste sentido, o domínio das correspondências grafofonêmicas regulares e o emprego de uma estratégia fonológica tanto na leitura quanto na escrita parecem ser os fundamentos que permitem às crianças nos anos iniciais do ensino fundamental a produção de narrativas escritas mais elaboradas (Abbot \& Berninger, 1993; Berninger et al., 2000).

O Português Brasileiro é uma língua relativamente transparente (Viário \& Guimarães-Filho, 2007). Como tal, seu aprendizado é favorecido pelo conhecimento das regularidades em nível fonológico como pelo desenvolvimento das habilidades de processamento fonológico que permitam o uso da decodificação e da codificação (Caravolas, 1993). A facilidade com que a criança é capaz de ler e grafar as palavras não se realiza sem que tenha havido a automatização do conhecimento das correspondências grafofonêmicas. Isto libera os recursos cognitivos que estariam a serviço do aprendizado do sistema de escrita para a o processamento dos aspectos macrotextuais no ato da leitura e da escrita (Graham \& Harris, 2000). No caso da escrita, tais recursos cognitivos auxiliam a estruturação de narrativas mais complexas durante a produção de histórias pelas crianças.

Em relação às dissociações entre leitura e escrita de palavras (Ehrie, 1997), chama atenção que a leitura proficiente de palavras irregulares parece mais importante do que a escrita de palavras irregulares para a produção escrita de histórias. Crianças com dificuldades na escrita de palavras irregulares ainda assim foram proficientes na escrita de histórias, sendo 54\% de suas histórias classificadas nas categorias IV e V. Por outro lado, crianças com habilidade regular na leitura de palavras irregulares tiveram apenas $35 \%$ das histórias classificadas nos níveis IV e V e $40 \%$ das histórias nos níveis mais elementares de estruturação da narrativa (categorias I e II).

$\mathrm{Na}$ análise das produções textuais, os erros ortográficos não foram analisados, uma vez que, mesmo com uma série de erros ortográficos de escrita, as crianças ainda assim poderiam atingir a categoria máxima de produção textual. Aliado a isso, no português existem muito mais irregularidades para a escrita do que para a leitura. A variável regularidade pode ter implicações muito maiores para a escrita, cujas regras são mais complexas e em número menor, do que para a leitura (Pinheiro \& Rothe-Neves, 2001).

Houve também diferenças nos critérios de construção das listas de leitura e de escrita de palavras. Na lista de palavras usadas na tarefa de escrita, a maioria (80\%) dos estímulos era de baixa frequência, ao contrário da leitura, em que metade era frequente e a outra metade não frequente. Apesar desta certa independência, o uso do conhecimento ortográfico na escrita depende do desenvolvimento de um léxico ortográfico para a leitura. A leitura por meio de pistas parciais (leitura visual rápida) forma bases insuficientes para a aquisição de representações ortográficas que garantam uma escrita precisa (Salles \& Parente, 2007).

Com os recursos de escrita que possuem - habilidades de escrita das palavras regulares e do emprego de estratégias fonológicas, as crianças podem escrever histórias mais complexas do ponto de vista macrolinguístico, mesmo que violando as convenções da ortografia. No caso 
da leitura, o conhecimento das irregularidades da língua permite à criança o acesso a textos com tramas narrativas mais complexas do que aquelas permitidas apenas pelo emprego de palavras regulares. Tal experiência de leitura permite melhor compreensão do gênero de texto narrativo e de seus elementos constituintes. O entendimento do gênero de texto narrativo adquirido em conformidade com as habilidades de leitura da criança permite a ela criar histórias escritas que incluem os elementos essenciais de produção de uma narrativa prototípica, mesmo que com dificuldades no domínio das convenções ortográficas.

Apesar da relação entre as habilidades textuais e a leitura e a escrita de estímulos isolados, é importante ressaltar que o domínio de estratégias fonológicas e ortográficas (conhecimentos lexicais) de leitura e de escrita de palavras não são suficientes por si sós para o domínio do esquema narrativo. As habilidades narrativas parecem derivar também de experiências, tanto na escola como no ambiente familiar, com textos (Lins e Silva \& Spinillo, 1998, 2000) e o desenvolvimento da consciência metatextual, constituída por meio de tal experiência.

De forma bastante simplificada, podemos compreender a escrita de histórias segundo um conjunto de saberes e de competências integrados pelo sistema de memória que permite a realização de operações linguístico-cognitivas necessárias para a análise (compreensão) e produção do texto (Abbot \& Berninger, 1993; Berninger et al., 2000). Inclusos em tais saberes e competências estão aqueles que examinamos no presente trabalho: habilidades metalinguísticas de análise fonológica e de consciência metatextual; processos de conceituação e de representações dos sistemas fonológico e ortográfico; habilidades de organização e coordenação do fluxo das ideias na elaboração de sequências narrativas e do emprego e eficácia das estratégias de leitura e de escrita no nível da palavra associadas à produção textual.

Por fim, reiteramos os limites do presente estudo. Não consideramos outros fatores já investigados na literatura, como motivação, contexto socioeconômico e familiar e ensino.

\section{Considerações finais}

A habilidade das crianças na produção escrita de textos foi bastante variável, caracterizando-se, na maioria, por produções (escrita) incompletas de histórias. Variável também foram as habilidades de leitura e escrita de palavras e pseudopalavras pelas crianças. A associação entre as diferentes habilidades nos níveis microtextuais (leitura e escrita de palavras) e as habilidades macrotextuais (organização da narrativa) sugerem que os diferentes níveis de processamento de texto devem ser desenvolvidos nas crianças (Berninger et al., 2000).

Salienta-se, ainda, a importância da avaliação dos processamentos textuais em crianças dissociadas do domínio da escrita das irregularidades ortográficas. Uma vez que as crianças adquirem os conhecimentos e as habilidades de escrita que permitam a legibilidade do texto que produzem, ou seja, o domínio das correspondências grafofonêmicas regulares e o emprego de estratégia fonológica, a sua preocupação com a coerência do texto e o desenvolvimento das habilidades criativas na produção de histórias podem e devem ser desenvolvidas.

\section{Children's textual production of stories and their relationship with the skill of reading and writing words/ pseudowords}

Abstract: The study describes the production of written stories by second grade children and compares them in subgroups classified by the skill of reading and writing words/pseudowords. The textual production of stories was classified in one of five categories. The results show that $54.6 \%$ of the sample reached intermediate categories (III and IV), characterized by the absence of a problem situation or only a sketch of it. There is a significant association between the word level skills and the narrative level of the text. Children who are skilled in reading and writing words/pseudowords are also skilled in producing written texts. The reverse is also true. The mastery of regular graph-phonemic correspondences in reading and writing seems to be important for the written production of narrative texts. However, irregular words reading skill seems more important than irregular written word skill to the textual production of stories.

Keywords: written language, production of stories, children, textual production, evaluation.

\section{La production d'histoires écrites par les enfants et leur relation avec les compétences en lecture et l'écriture de mots/pseudomots}

Résumé: L'étude décrit la production écrite d’histories par enfants avec trois années de scolarité dans écoles publiques et les compare entre sous-groupes de compétences em lecture et écriture de mots/pseudomots. Les productions textuelles ont été regroupés em cinq catégories: $54,6 \%$ de l'échantillon atteint catégories intermédiaires (III et IV), caractérisé par l'absence d’une situation problématique ou juste une esquisse de ça. Il existe une association significative entre les compétences dans le niveau de mot et la production de texte narratif écrit. Les enfants qui sont qualifiés dans la lecture et l'écriture de mots/pseu- 
domots sont qualifiés dans la production de texte écrit aussi. L'inverse est également vrai. Le domaine des correspondances de graphèmes et phonèmes reguliérs em lecture et écriture semble être important pour la production écrite de texte narratif. Toutefois, le compétence en lecture de mots irréguliers semble être plus important que en le écriture de mots irréguliers par la production écrit de l'histoire.

Mots-clés: la langue écrite, l'histoire écrite, les enfants, la production textuelle, de l'évaluation.

\section{La producción escrita de historias por niños y su relación con las habilidades de lectura y escritura de pal- abras/pseudopalabras}

Resumen: Este estudio describe la producción escrita de historias hechas, a partir de secuencias de imágenes, por los niños del tercer grado de escuelas públicas y la compara con el desempeño entre los subgrupos clasificados pelas habilidades de lectura y escritura de palabras y pseudopalabras. Las producciones textuales fueron agrupadas en cinco categorías: el 54,6\% de la muestra llegó a las categorías intermedias (III y IV), que se caracterizan por la ausencia de una situación problemática o simplemente de un esbozo. Existe una asociación significativa entre las habilidades en el nivel de palabra y la producción de un texto narrativo escrito. Los niños que son expertos en la lectura y escritura de palabras y pseudopalabras también son expertos en la producción de un texto escrito, al revés también es cierto. El dominio de las correspondencias grafofonemicas regulares en la lectura y escritura parece ser importante a la producción escrita de un texto narrativo. Sin embargo, para producir historias escritas la habilidad en la lectura parece más importante que en la escrita de palabras irregulares.

Palabras clave: lengua escrita, la escritura de historias, niños, producción textual, evaluación.

\section{Referências}

Abbott, R. D., \& Berninger, V. W. (1993). Structural equation modeling of relationships among developmental skills and writing skills in primary - and intermediate-grade writers. Journal of Educational Psychology, 85, 478-508.

Belinchón, M., Igoa, J. M., \& Rivière, A. (2000). Psicología del lenguaje. Investigación y teoría. Madrid: Trotta.

Berman, R. A. (2008). The psycholinguistics of developing text construction. Journal of Child Language, 35, 735-771.

Berninger, V. W., Vaughan, K., Abbott, R. D., Begay, K., Coleman, K. B., Curtain, G., Hawkins, J. M., \& Graham, S. (2002). Teaching spelling and composition alone and together: Implications for the simple view of writing. Journal of Educational Psychology, 94, 291-304.

Brandão, A. C. P., \& Spinillo, A. G. (2001). Produção e compreensão de textos em uma perspectiva de desenvolvimento. Estudos de Psicologia, 6(1), 51-62.

Bruning, R., \& Horn, C. (2000). Developing motivation to write. Educational Psychologist, 35, 25-37.

Capellini, S. A., \& Smythe, I. (2008). Protocolo de avaliação de habilidades cognitivo-lingüisticas: livro do profissional e do professor. Marília, SP: Fundepe.

Capovilla, F. C., Smythe, I., Capovilla, A. G., \& Everatt, J. (2001). Adaptação brasileira do "Internacional Dyslexia test": perfil cognitivo de crianças com escrita pobre. Temas sobre Desenvolvimento, 10(57), 30-37.

Caravolas, M. (1993). Language-specific influences of phonology and orthography on emergent literacy. In J. Altarriba (Ed.), Cognition and culture: A cross-cultural approach to psychology (pp. 125-140). Amsterdam: Elsevier.
Correa, J. (2010). Representações e competências desenvolvidas pela criança no aprendizado da escrita. In M. J. M. Luna, A. G. Spinillo \& S. G. Rodrigues (Orgs.), Leitura e produção de texto (pp. 13-49). Recife: Ed. da UFPE.

Correa, J., \& Dockrell, J. E. (2007). Unconventional word segmentation in Brazilian children's early text production. Reading and Writing, 20, 815-831.

Correa, J., \& MacLean, M. (1999). Aprendendo a ler e a escrever: a narrativa das crianças sobre a alfabetização. Psicologia Reflexão e Crítica, 12, 273-286.

Costa, S. R. (2008). Dicionário de gêneros textuais. Belo Horizonte, MG: Autêntica.

Ehri, L. C. (1997). Learning to read and learning to spell are one and the same, almost. In C. A. Perfetti, L. Rieben \& M. Fayol (Eds.), Learning to spell: Research, theory and practice across languages (pp. 237-269). Hillsdale, NJ: Lawrence Erlbaum.

Ferreira, S. P., \& Correa, J. (2008). A influência de diferentes contextos de intervenção na escrita de histórias por crianças. Estudos de Psicologia, 25(4), 547-555.

Graham, S., \& Harris, K. R. (2000). The role of selfregulation and transcription skills in writing and writing development. Educational Psychologist, 35(1), 3-12.

Gregg, N., \& Mather, N. (2002). School is fun at recess: Informal analyses of written language for students with learning disabilities. Journal of Learning Disabilities, $35,7-22$.

Leal, T. F., \& Luz, P. S. (2001). Produção de textos narrativos em pares: reflexões sobre o processo de interação. Educação e Pesquisa, 27(1), 27-45. 
Leybaert, J., Alégria, J., Deltour, J., \& Skinkel, R. (1997). Aprender a ler: o papel da linguagem, da consciência fonológica e da escola. In J. Grégoire \& B. Piérart (Orgs.), Avaliação dos problemas de leitura: os novos modelos teóricos e suas implicações diagnósticas (pp. 143-166). Porto Alegre, RS: Artes Médicas.

Lins e Silva, M. E., \& Spinillo, A. G. (1998). Uma analise comparativa da escrita de histórias pelos alunos de escolas públicas e particulares. Revista Brasileira de Estudos Pedagógicos, 79(193), 5-16.

Lins e Silva, M. E., \& Spinillo, A. G. (2000). A influência de diferentes situações de produção na escrita de histórias. Psicologia: Reflexão e Crítica, 13(3), 337-350.

Marcuschi, L. A. (2008). Produção textual, análise de gêneros e compreensão. São Paulo, SP: Parábola.

Pessoa, A. P. P., Correa, J., \& Spinillo, A. G. (2010). Contexto de produção e o estabelecimento da coerência na escrita de histórias por crianças. Psicologia Reflexão e Crítica, 23(2), 253-260.

Pinheiro, A. M. V. (1996). Contagem de frequência de ocorrência de palavras expostas a crianças na faixa de pré-escola e séries iniciais. Software produzido pela Associação Brasileira de Dislexia - ABD.

Pinheiro, A. M. V., \& Rothe-Neves, R. (2001). Avaliação cognitiva de leitura e escrita: as tarefas de leitura em voz alta e ditado. Psicologia: Reflexão e Crítica, 14(2), 399408.

Rodrigues, M. R. F., Queiroz, S. S., \& Alencar, H. M. (2008). Possíveis influências da elaboração de desenhos sobre narrativas infantis. Revista Semestral da Associação Brasileira de Psicologia Escolar e Educacional, 12(1), 203-219.

Rojas-Drummond, S. M., Albarrán, C. D., \& Littleton, K. S. (2008). Collaboration, creativity and the co-construction of oral and written texts. Thinking Skills and Creativity, 3, 177-191.

Salles, J. F. (2005). Habilidades e dificuldades de leitura e escrita em crianças de $2^{a}$ série: abordagem neuropsicológia cognitiva (Tese de Doutorado).
Programa de Pos-Graduaçao em Psicologia, Universidade Federal do Rio Grande do Sul, Porto Alegre, RS.

Salles, J. F., Freitas, L. B. L., \& Parente, M. A. M. P. (2010). Leitura/escrita em crianças: comparações entre grupos de diferentes escolas públicas. Paidéia, 20, 335-344.

Salles, J. F., \& Parente, M. A. M. P. (2002). Processos cognitivos na leitura de palavras em crianças: relações com compreensão e tempo de leitura. Psicologia: Reflexão e Crítica, 15(2), 321-331.

Salles, J. F., \& Parente, M. A. M. P. (2007). Avaliação da leitura e escrita de palavras em crianças de $2^{\mathrm{a}}$ série: Abordagem neuropsicológica cognitiva. Psicologia: Reflexão e Crítica, 20, 218-226.

Salles, J. F., \& Parente, M. A. M. P. (2008). Variabilidade no desempenho em tarefas neuropsicológicas entre crianças de $2^{\mathrm{a}}$ série com dificuldades de leitura e escrita. Arquivos Brasileiros de Psicologia, 60(1), 32-44.

Sharples, M. (1999). How we write: Writing as creative design. London: Routledge.

Smythe, I., \& Everatt, J (2000). Dyslexia diagnosis in different languages. In L. Peer \& G. Reid (Orgs.), Multilingualism, literacy and dyslexia (pp. 12-21). London, David Fulton Publishers.

Spinillo, A. G. (2001). A produção de histórias por crianças: a textualidade em foco. In J. Correa, A. Spinillo \& S. Leitão (Orgs.), Desenvolvimento da linguagem: escrita e produção textual (pp. 73-116). Rio de Janeiro: NAU.

Spinillo, A. G., \& Simoes, P. U. (2003). O desenvolvimento da consciência metatextual em crianças: questões conceituais, metodológicas e resultados de pesquisas. Psicologia: Reflexão e Crítica, 16(3), 537-546.

Viário, M. E., \& Guimarães-Filho, Z. O. (2007). Análise quantitativa da frequência dos fonemas e estruturas silábicas portuguesas. Estudos Linguísticos, 36, 28-36.

Weschsler, D. (1949). Weschsler Intelligence Scale for Children - WISC. Pshychological. New York, USA.

Yorkston, K. M., Jaffe, K. M., Polissar, N. L., Liao, S., \& Fay, G. C. (1997). Written language production and neuropsychological function in children with traumatic brain injury. Archives Physical Medicine Reabilitation, 78, 1096-1102. 